\title{
CARACTERIZACIÓN DEL ÁREA FINANCIERA EN EL SECTOR INDUSTRIAL DEL DEPARTAMENTO DE BOYACÁ ${ }^{1}$
}

\section{Jorge Enrique Romero Muñoz ${ }^{2}$ Danithsa Vanessa Vega Ávila ${ }^{3}$}

Para citar este artículo: Romero, J. y Vega, D. (2015). "Caracterización del área financiera en el sector industrial del departamento de Boyacá". Inquietud Empresarial. Vol. XV (1), pp. 15-49

Fecha de recepción: 14 de noviembre de 2014 Fecha de aceptación: 16 de febrero de 2015

\footnotetext{
1 Artículo de investigación científica y tecnológica como resultado del proyecto de investigación titulado "Diagnóstico del área financiera de los diferentes sectores de la economía en el departamento de Boyacá", desarrollado dentro del grupo de investigación: Gerencia del Valor y Finanzas de la Escuela de Administración de Empresas de la UPTC Tunja.

2 Administrador de Empresas UPTC. Especialista en Finanzas UPTC. Magíster en Administración. Universidad Externado de Colombia, Docente UPTC. jenromu@hotmail.com

3 Administradora de Empresas UPTC., vanessa.vega.avila@hotmail.com
} 


\title{
RESUMEN
}

El presente artículo busca realizar un análisis de la gestión financiera de las empresas del sector industrial del departamento de Boyacá. Su realización incluye la aplicación de un cuestionario a una muestra aleatoria de empresarios, la cual muestra resultados en cuanto a las variables de contabilidad, presupuestos, tributaria, costos, análisis de la gestión financiera, capital de trabajo y entorno financiero. Luego del proceso de reconocimiento de la gestión financiera, se realiza un análisis de las principales fortalezas y debilidades de las empresas del sector, con relación a las variables citadas, para así plantear las principales estrategias a desarrollar por parte de los empresarios.

\section{PALABRAS CLAVE}

Gestión, finanzas, contabilidad, costos, tributaria, presupuestos, capital de trabajo, entorno financiero, fortalezas, debilidades y estrategias.

\section{Financial area characterisation in the industrial sector of the Boyacá department}

\begin{abstract}
This article seeks to make an analysis of the financial management of companies in the industrial sector of Boyacá. By conducting surveys to a random sample of employers, which threw the results in terms of the variables accounting, budgeting, tax, costs, analysis of financial management, working capital and financial environment. After the process of recognition of financial management, an analysis of the main strengths and weaknesses of the companies in the sector will be made, so as to raise the main strategies developed by entrepreneurs
\end{abstract}

\section{KEY WORDS}

Management, finance, accounting, costs, tax, budgeting, working capital, financial environment, strengths, weaknesses and strategies. 


\section{Caracterização da área financeira no setor industrial do departamento de Boyacá}

\section{RESUMO}

O presente artigo busca realizar uma anãlises da gestão financeira das empresas do setor industrial do departamento de Boyacá. Sua realização inclui a aplicação de um questionário a uma amostra aleatória de empresários, a qual mostra resultados em quanto as variáveis de contabilidade, orçamento, tributária, custos, análises da gestão financeira, capital de trabalho e entorno financeiro. Logo do proceso de reconhecimento da gestão financeira, se realiza uma análise das principais fortalezas e debilidades das empresas do setor, com relação às variáveis citadas, para assim solucionar as principais estratégias a desenvolver por parte dos empresários.

\section{PALAVRAS CHAVE}

Gestão, finanças, contabilidade, custos, tributário, orçamentos, capital de trabalho, entorno financeiro, fortalezas, debilidades e estratégias.

\section{INTRODUCCIÓN}

El presente trabajo se desenvuelve en una correlación de los análisis teóricos efectuados al sector industrial, en el cual se hace un despliegue de todos los ítems tratados en las diferentes áreas empresariales, con lo cual se busca destacar que el análisis de la gestión financiera ha sido casi nulo para el sector.

Luego de ello se realiza una breve descripción de los principales conceptos a tratar en el desarrollo del proyecto, el cual se plantea ser efectuado mediante la aplicación de una encuesta detallada compuesta de preguntas cerradas; para así posteriormente realizar la selección de la base de datos de las Cámaras de Comercio de Tunja, Duitama y Sogamoso, e identificar la muestra estratificada que permita la correcta ejecución de las encuestas.

Finalmente se realiza un análisis de la gestión financiera de las empresas del sector industrial mediante la inferencia de los resultados obtenidos, para así clasificarlos en fortalezas y debilidades del sector y plasmar las estrategias necesarias para convertir las debilidades en fortalezas. 


\section{Referentes Teóricos}

Al centrarse en el concepto de la administración financiera, podemos observar que Calvopiña (2010), plantea que los gestores de dicha actividad deben focalizar sus esfuerzos en encontrar la mejor forma de adquisición, financiamiento y administración de los activos para la toma de decisiones. Es decir, que el proceso del análisis financiero se encuentra presente en toda la empresa, puesto que la gestión no consiste solamente en buscar un funcionamiento financiero estable de la empresa, sino complementarlo con un correcto análisis del mismo.

Dentro del proceso financiero de toda empresa, debe existir una coherencia entre la parte operativa y contable como lo son la realización de los estados financieros, los indicadores, los presupuestos etc., y el análisis de los mismos. Cuando las organizaciones se dedican a cumplir con el proceso de elaborar todos los protocolos financieros y no abordan su razón de ser, la causa de su existencia de su mejora o de las perdidas, se está desaprovechando la mitad de la actividad financiera; puesto que se anula el proceso de convertir los números en realidades, transformando así los resultados obtenidos en métodos, estrategias y técnicas que le permitirán a la empresa mejorar y lograr causar un impacto en el mercado, antes que sus procesos internos se lo indiquen debe basar sus estrategias en un pronóstico de su situación. (Ortiz, 2006).

Cada vez que una empresa reúne todos los aspectos operativos y analíticos en su gestión financiera, está realizando una generación de valor al destacar un aspecto diferenciador que la mayoría de empresas no realizan e igualmente está permitiendo incorporar al sistema empresarial un proceso de desarrollo e innovación.

Por otro lado, si se revisan las variables a analizar en la gestión financiera, se debe destacar el hecho de que no es suficiente quedarse con las variables financieras básicas, los procesos de análisis deben avanzar y compilar todas las herramientas existentes para mejorar los procesos. Los empresarios deben permanecer conectados con los entes externos a sus negocios, para así estar al día de los cambios realizados en las normas y en los avances que se han realizado en los diferentes niveles empresariales.

Dentro de las investigaciones realizadas al sector industrial, se puede encontrar una diversa gama de trabajos referentes a las diferentes áreas 
de las empresas. Dentro de los trabajos investigativos realizados se encuentran:

- El trabajo de Espinosa (2013), revela que el marco normativo y financiero de descentralización abre la posibilidad de consolidar procesos regionales de desarrollo y así mismo destaca la necesidad de aprovechar los procesos de globalización, tratados de libre comercio, avances tecnológicos e innovación con el fin de ser un territorio mucho más competitivo y sostenible.

El trabajo propone los siguientes escenarios: 1. Región competitiva e integrada al mundo. 2. Región en manos ajenas. 3. Región insostenible y 4. Región de emigración; los cuales revelan los posibles futuros a ocurrir, destacando que el escenario deseado sería el primero, para el cual se deben llevar a cabo las 7 estrategias planteadas e integradas a la institucionalidad gubernamental del departamento.

- El estudio del Departamento Nacional de Planeación (2007) revela que a pesar de la importancia del sector industrial alrededor de Tunja, Duitama y Sogamoso y el repentino crecimiento del sector industrial de transformación, que por cierto ha ganado gran participación en el PIB departamental, la tendencia en Boyacá es a una producción agropecuaria, lo que muestra que para la mitad de la población aproximadamente continua siendo la principal actividad económica.

La tendencia agropecuaria de Boyacá, logra contrastar las estadísticas a nivel nacional, debido a que ésta no se ha urbanizado de manera acelerada como si ha ocurrido en el resto del país y por el contrario se sigue manejando una tendencia al crecimiento rural, por lo cual se propone transferir tecnología, conocimiento y buenas prácticas agrícolas para que el sector pueda seguir en crecimiento, e igualmente se pretende impulsar el sector industrial a fin de que logre llegar a ser representativo en la región.

- Uno de los trabajos más conectados al área de finanzas es el realizado por Correa y otros (2009), el cual busca mejorar las condiciones actuales de las empresas mediante una propuesta de corte financiero, que optimiza los recursos escasos y crea el modelo de Gestión Financiera Integral uniendo cinco componentes esenciales: administrativo, técnico, legal, internacional y contable financiero. 
Se puede señalar que es de suma importancia para el modelo, que las empresas comiencen a manejar un registro de las actividades, para así mantener información actualizada que fundamente la toma de decisiones. La herramienta se implementa mediante resultados cuantitativos y cualitativos para mantener a las empresas en un entorno internacionalizado, comprometiendo a los profesionales contables a aportar en el proceso de generación de valor de las empresas.

- El trabajo de Burbano y otros (2006), se dirige a las Pymes del corredor industrial de Boyacá, que se componen en un $98 \%$ del sector metalmecánico y que abarca en un 29\% Tunja, 36\% Sogamoso y 35\% Duitama. A pesar de ser microempresas con gran participación en la industria, no tienen ninguna formación empresarial, deben sus logros al completo empirismo y al traspaso de conocimiento de generación en generación. Por lo cual presentan un total desconocimiento financiero, que las hace incapaces de sostenerse en el mercado y conlleva a que su manejo contable y de costeo sea casi nulo; es así como la toma de decisiones de estas empresas es realizada de forma espontánea e intuitiva haciéndolas poco atractivas en el mercado financiero y dificultando el acceso a los créditos de fomento del gobierno.

- El trabajo de Torres (2012), muestra cómo las áreas de Gestión Humana de las empresas entre Duitama y Sogamoso logran agregan valor a las mismas aportando grandes mejoras en la productividad; debido a que las estrategias de las empresas están alineadas con las del área de Gestión Humana. Así mismo se plantean planes de mejoramiento para los gerentes de la Gestión Humana, debido a la naturaleza del área y a la capacidad que poseen de generar cambios positivos en las empresas. Es así como la investigación revela que el modelo propuesto por Calderón es compatible con la situación en Boyacá dado a que sí se confronta el comportamiento de las empresas nacionales con las Multinacionales, se puede observar que éstas últimas destinan gran importancia al proceso de selección del personal y afirman el papel de liderazgo y pertenencia que logra guiar a los demás empleados.

Es así como se concluye que desde el área de Gestión Humana, se debe poner más atención a los empleados se deben hacer esfuerzos por dale un empoderamiento al personal y hacerles saber que son más que un "recurso" y estimularlos para que cumplan los objetivos estratégicos 
de las organizaciones de una forma satisfactoria y agradable.

- El trabajo de Mojica (2010) se basa en una mirada prospectiva del sector lácteo, en la cual se muestra la existencia de diferentes escenarios a los cuales tenemos la posibilidad de llegar; lo interesante es que el solo hecho de que exista la posibilidad, no lo hace alcanzable. Para que el sector lácteo en Colombia crezca y logre alcanzar elevados estándares de calidad, sobrepasar las ideas de negocio y llegar a otros países, es necesario implementar actividades investigativas y organizacionales que permitan desarrollar alguno de los futuros existentes.

El autor apuesta por alcanzar la alternativa o el futuro de la "leche saludable" buscando cumplir todas las expectativas, económicas, administrativas y sociales. Igualmente invita a todos los empresarios del sector lácteo a hacer parte de este cambio nacional que se requiere para poder mejorar y crecer como sector.

A pesar de ello, existen grandes obstáculos en el sector lácteo, que impiden el crecimiento y desarrollo del mismo, como lo es la fabricación de leche en polvo, alimento para bovinos, entre otros; lo cual lleva a que se presenten grandes dificultades de expansión y por ende se acceda a la importación de dichos productos y como consecuencia se impide el incremento del superávit comercial. Las empresas deben comenzar a desarrollar sus productos y superar los obstáculos del camino, porque de lo contrario se está desperdiciando un sector que es muy llamativo al crecimiento.

Es así como se observa que la mayoría de investigaciones del sector industrial no apuntan a la realización de mejoras en la gestión financiera, sino al mejoramiento productivo de las empresas, incremento de las ventas y expansión empresarial, por lo cual es de vital importancia la realización del presente diagnóstico.

\section{METODOLOGÍA}

El tipo de investigación es descriptiva, por cuanto a través de los datos suministrados por las empresas de su realidad empírica, se describen las características de cada subsector en cada una de las categorías de análisis definidas para dar un concepto integral del desempeño del área financiera. 
Las categorías de análisis a estudiar son: a) contabilidad, b) costos, c) presupuestos, d) capital de trabajo, e) tributación, f) gestión financiera y g) el conocimiento del entorno financiero.

Estas categorías integralmente dan cuenta del direccionamiento administrativo que una empresa desempeña en el área financiera y por tanto las preguntas relacionadas en el instrumento de recolección de información diseñado corresponden a las variables específicas que dan cuenta de cada una de las 7 categorías mencionadas.

El método de investigación integra la inducción y la deducción por cuanto el planteamiento de las categorías de análisis se construyó de manera inductiva al partir de los conceptos generales que definen el manejo de un área financiera para analizar de manera particular el comportamiento de dichas variables en empresas de unos subsectores económicos de manera particular.

Las fuente principal del trabajo de campo para la recolección de información fueron las empresas formalmente registradas en las cámaras de comercio de Tunja, Duitama y Sogamoso que fueron seleccionadas de manera aleatoria del conjunto de empresas registradas en los subsectores económicos establecidos previamente.

El instrumento de recolección de información es un cuestionario que consta de 60 preguntas cerradas, de respuesta Si o No para el empresario. Adicionalmente se ubicó una tabla de valoración de 1 a 4 sobre las repuestas del empresario, para que pudiera establecer en una escala cuantitativa en qué nivel de desempeño se encuentra la empresa de acuerdo a cada pregunta planteada así:

A fin de poder cuantificar las respuestas de los empresarios y lograr identificar las principales fortalezas y debilidades presentes en el sector industrial.

Según el muestreo estratificado, se deben realizar 28 encuestas en Tunja, 28 en Duitama y 24 en Sogamoso, según la proporción de las empresas existentes en la totalidad del sector. 


\section{Resultados de la caracterización del sector}

A continuación se presentan los resultados globales de la investigación a fin de poseer un panorama general del sector industrial.

\section{Naturaleza de las empresas}

Propiedad familiar: Como se puede observar en el Figura 1, se encontró que 68 de las empresas encuestadas son familiares, lo cual revela que la tendencia del sector es realizar proyectos empresariales en asociación con los familiares.

Figura 1. Empresas familiares del sector industrial

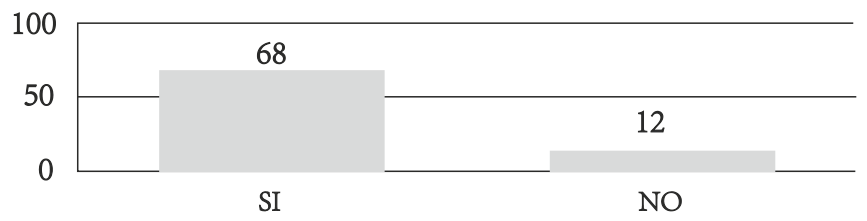

Fuente: Elaboración propia

Personería jurídica: Como muestra la Figura 2, más de 50 empresas encuestadas respondieron estar catalogadas como persona natural, lo cual muestra que son muy pocas las empresas que manejan sociedades con terceros para la creación y gestión de las mismas. El presente resultado concuerda con el obtenido anteriormente ya que al ser la mayoría de las empresas familiares no se realizan inversiones externas.

Figura 2. Personería jurídica del sector industrial

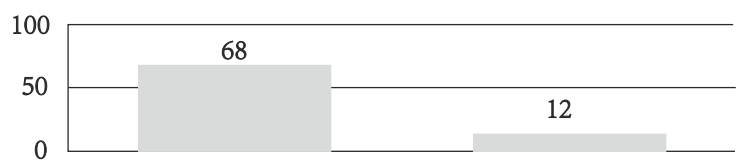

Fuente: Elaboración propia 


\section{Información de productos o servicios}

Se puede observar que el promedio de productos que se ofrecen no varía demasiado según los ingresos, lo que sí se puede resaltar es el hecho de que las empresas con menores ingresos ofrecen una proporción mayor de productos debido a que estas esperan poder incrementar las ganancias con un portafolio más amplio de productos. Paralelo a ello se encuentra que las empresas con mayores ingresos solo producen dos o incluso un solo producto puesto que se dedican totalmente al mismo e implementan todos los esfuerzos empresariales a la ventaja competitiva del mismo.

Figura 3. Promedio de los productos ofrecidos en el sector industrial según los ingresos empresariales

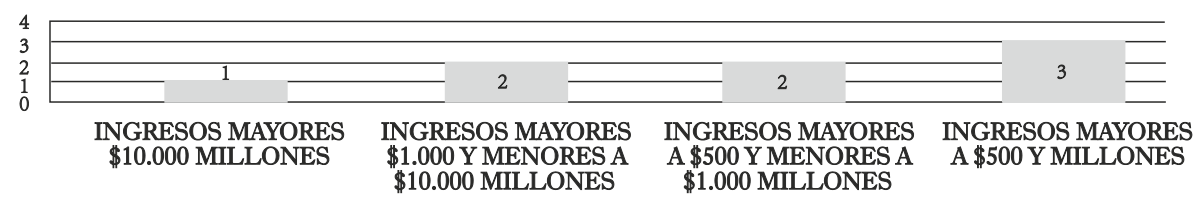

Fuente: Elaboración propia

\section{Nivel de ingresos operacionales}

Figura 4. Empresas de acuerdo al nivel de ingresos operacionales

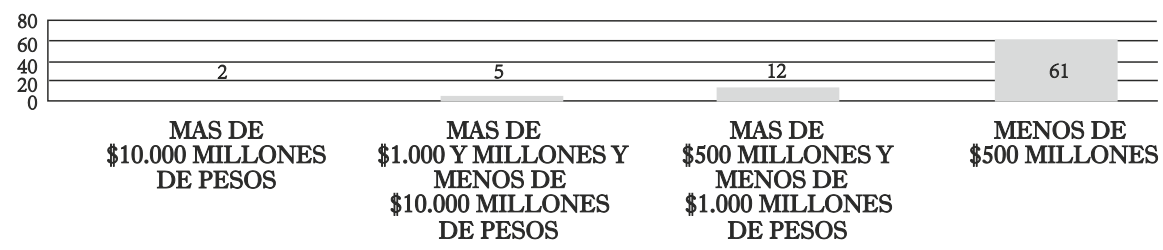

Fuente: Elaboración propia

Como se observa en el grafico anterior, la mayor proporción de empresas encuestadas son las que poseen el menor rango de ingresos que se estableció como estándar de medición. Sin embargo cabe destacar que esta es una respuesta acorde con que la mayoría de las empresas sean familiares y su personería jurídica es natural, lo cual obliga a que sus ingresos no sean muy elevados. 


\section{Consolidado de las variables analizadas en el sector}

El resultado de las variables analizadas se expresa mediante una figura radial, la cual permite observar los puntos críticos de la gestión financiera del sector industrial. Estos resultados se obtuvieron del consolidado de la totalidad de preguntas encontradas en cada una de las siete variables a analizar, las cuales permitieron arrojar un resultado final.

Figura 5. Diagnóstico empresarial del sector industrial

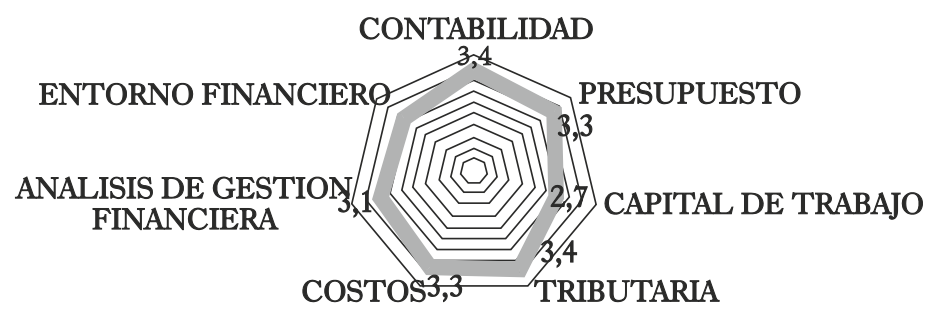

Fuente: Elaboración propia

La presente figura muestra la gestión realizada por la totalidad de las empresas en el sector industrial, lo cual revela que el mejor desempeño y comprensión se encuentra en las áreas de Contabilidad y Tributaria, con una calificación de 3.4 sobre 4.0, seguido de Presupuestos y Costos, los cuales obtuvieron una calificación de 3.3. Se observa que se posee una fortaleza en 4 de las 7 variables observadas, pero es de analizar el hecho de que la variable "Análisis de la gestión financiera" obtuviera un porcentaje más bajo de 3.1. 


\section{Análisis realizado a cada una de las variables}

\section{Contabilidad}

En cuanto a la variable contabilidad su calificación como variable promedio fue de 3.4 y en cuanto a la división por ingresos, podemos observar que el comportamiento de es el siguiente:

Figura 6. Variable contabilidad según el nivel de ingresos

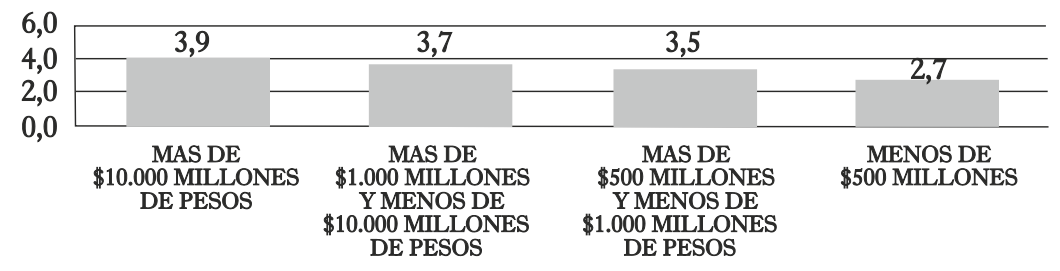

Fuente: Elaboración propia

La mejor calificación la obtuvieron las empresas con mayores ingresos (más elevado y satisfactorio. Se observa el descenso en cuanto a la calificación de la variable el cual se mantiene en dos puntos para las dos siguientes clasificaciones de ingresos, mostrando así que a pesar de que su calificación no es tan elevada como la de las empresas con mayores ingresos, sigue siendo un valor estable y considerablemente positivo. Finalmente las empresas con menos de 500 millones de pesos son las que poseen la menor calificación de esta variable obteniendo un 2.7.

A fin de ampliar un poco más la anterior explicación se hará un recuento general de las subvariables analizadas en la variable de contabilidad y los promedios alcanzados en cada una de ellas.

$\checkmark$ Se observó que el $98 \%$ de la totalidad de los encuestados registran de manera permanente todas las operaciones que se realizan en la empresa. Los encuestados con ingresos de más de 10.000 millones de pesos alcanzaron un $100 \%$ de cumplimiento en dicha pregunta.

$\checkmark$ El 100\% de las empresas afirmó conservar de manera adecuada todos los soportes de las operaciones realizadas como facturas, recibos etc., este es uno de los aspectos que logró una calificación positiva en cuanto al sector en general. 
$\checkmark$ El 96\% de las empresas analizadas en el sector industrial afirman llevar contabilidad en la empresa.

$\checkmark$ En cuanto a los estados financieros que poseen las empresas, solo el $13 \%$ obtuvo una calificación negativa para este aspecto. Así mismo los principales estados financieros que las empresas llevan en el sector son:

Figura 7. Estados financieros que poseen las empresas del sector industrial

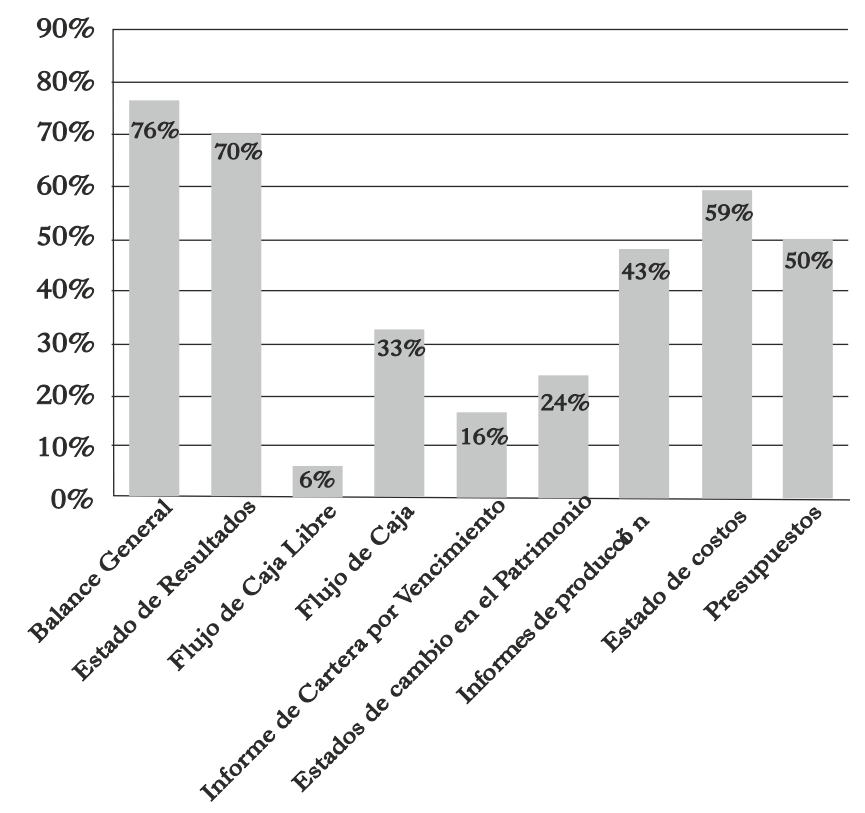

Fuente: Elaboración propia

$\checkmark$ Solo el $14 \%$ afirmó no poseer los estados financieros actualizados, mientras que el otro $86 \%$ aseveró si poseerlos actualizados y con máximo un mes de retraso.

$\checkmark$ El 100\% de los empresarios encuestados afirmó que procuraba poseer información actualizada cada día. Igualmente ésta es otra de las preguntas que contribuyó con la elevada calificación de la variable contabilidad 
$\checkmark$ En cuanto a si el gerente evalúa y examina de forma permanente los estados financieros a fin de detectar incorrecciones el $89 \%$ de los empleados afirmó realizarlo.

$\checkmark$ Solo el 64\% de los encuestados afirmó poseer un profesional en el tema contable que realice la contabilidad, lo cual es una de las principales falencias de esta variable, debido al hecho de que solo el profesional contable maneja ciertas pericias que le permiten crecer a la empresa.

$\checkmark$ En concordancia con lo anterior el mismo 64\% de los encuestados afirmó poseer criterios claros para seleccionar el contador de la empresa.

$\checkmark$ El 8\% de los encuestados afirman no llevar su contabilidad de acuerdo con las normas contables colombianas.

$\checkmark$ Finalmente una de las preguntas más relevantes en este extracto de la encuentra, es el hecho de que el $95 \%$ de los empresarios toma sus decisiones basándose en los estados financieros. Revelando la figura 8 que las empresas de más de 10.000 millones de pesos alcanzaron la máxima calificación de dicha variable, seguida por un 3.5 de las empresas con más de 500 millones y menos 1.000 millones de pesos.

Figura 8. Toma de decisiones basada en los estados financieros según el nivel de ingresos

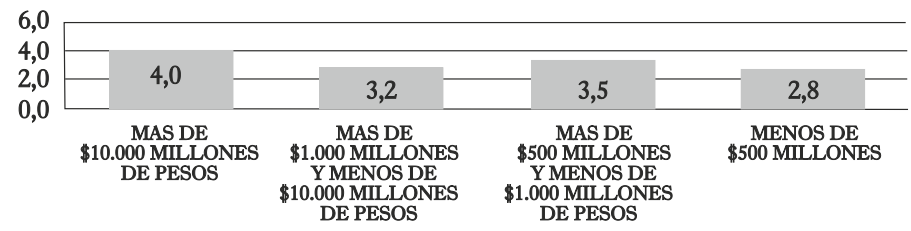

Fuente: Elaboración propia

Como lo muestra el comportamiento de las preguntas realizadas a la variable de contabilidad, los resultados obtenidos se deben principalmente a que en la mayoría de los aspectos encuestados, las empresas con mayores ingresos poseían calificaciones del $100 \%$, mientras que las empresas con menos ingresos no alcanzan porcentajes tan elevados; principalmente por el hecho de no poseer un profesional contable que lleve a cabo dicha gestión y por ende poseían gran desconocimiento e incumplimiento de los 
aspectos mencionados.

Así mismo dentro de los factores que contribuyeron a que las empresas con mayores ingresos alcanzaran una mejor calificación se encuentra el hecho de que poseen un registro de todas sus actividades, conservan los soportes de la misma y toman sus decisiones basándose en los estados financieros.

\section{Presupuestos}

La variable de presupuesto obtuvo una calificación en el sector de 3.3, la cual como lo muestra el grafico 9 se vio principalmente elevada por las empresas con mayores ingresos (más de 10.000 millones de pesos y más de 1.000 millones de pesos y menos de 10.000), debido a su elevada calificación de 3.6 .

Figura 9. Variable presupuestos según el nivel de ingresos

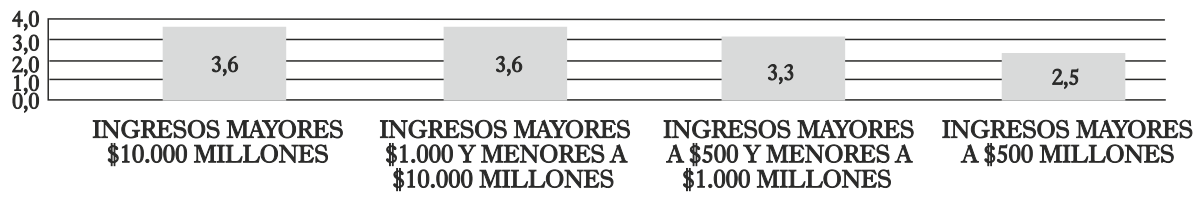

Fuente: Elaboración propia

A continuación se realizara un análisis de las preguntas realizadas en la presente variable a fin de conocer los principales aspectos que le permitieron la obtención de los anteriores resultados.

$\checkmark$ En cuanto al aspecto de las empresas que en verdad poseían un proceso de presupuestación, se observó que el $75 \%$ de este si lo asumían.

$\checkmark$ Así mismo el 75\% de los empresarios afirmó soportar sus presupuestos de ventas en investigación objetiva del mercado.

$\checkmark$ En cuanto a la utilización de herramientas para el presupuesto de ventas, el 78\% de los encuestados afirmó utilizar las siguientes:

- Herramienta de pronóstico en un 4\%

- Herramienta de análisis estadístico en un 10\% 
- Herramienta de análisis de series históricas y bases de datos de la empresa en un $64 \%$

Figura 10. Herramientas que implementan las empresas para el presupuesto de ventas

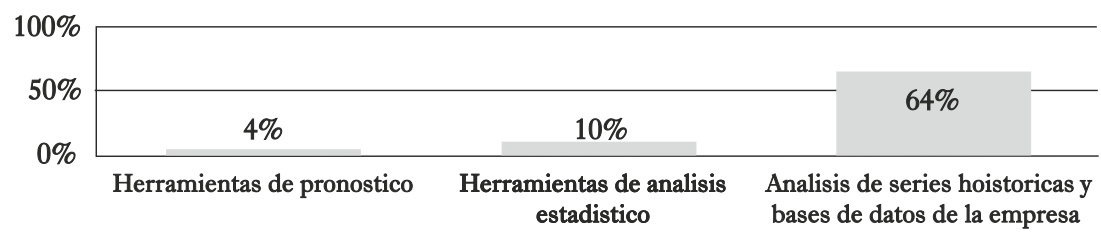

Fuente: Elaboración propia

Se observa que de ese $78 \%$ de empresas que utilizan las herramientas de presupuesto, el $64 \%$ prefiere la implementación de análisis de series históricas y bases de datos de la empresa, por comodidad y desconocimiento de la implementación de las otras dos herramientas.

$\checkmark$ En cuanto al aspecto de la realización, estructura y claridad de los presupuestos se obtuvo un $84 \%$ de las empresas que lo implementaba y dentro de los presupuestos más realizados se encuentra:

- Costos de producción con un 70\% de las empresas.

- Gastos y obligaciones financieras con un 66\% de las empresas.

- Gastos de administración con un 65\% de las empresas

- Obligaciones tributarias con un 64\%de las empresas.

- Gastos de ventas $61 \%$ de las empresas.

Dentro de los presupuestos de menor realización se encuentran los proyectos de inversión, proyectos de ampliación, reposición de activos fijos y recaudos con menos de un $20 \%$ de las empresas. 
Figura 11. Presupuestos que elaboran las empresas del sector industrial

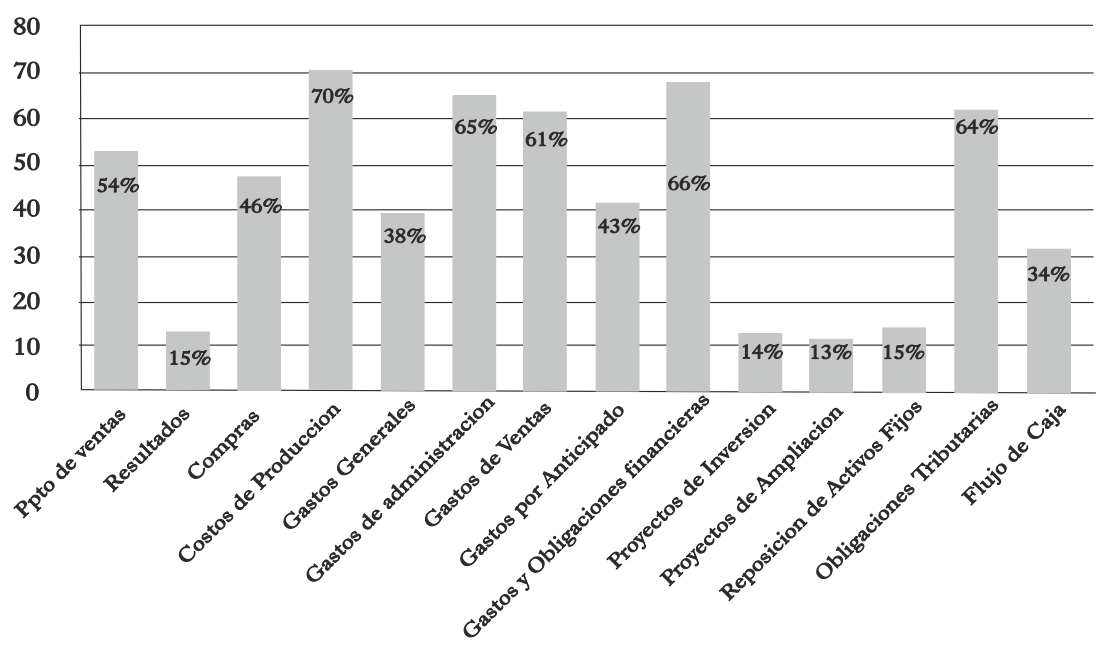

Fuente: Elaboración propia

$\checkmark$ Otro de los aspectos que obtuvo mayor calificación y que contribuyó con la calificación final de la variable es el hecho de que el $84 \%$ de las empresas compara los presupuestos con la realidad de manera permanente y dichas comparaciones son fuente de corrección.

$\checkmark$ El aspecto que mayor calificación obtuvo dentro de esta variable es el hecho de que el $96 \%$ de las empresas determinan las necesidades de capital de trabajo. Este factor es uno de los más importantes en la variable.

$\checkmark$ Así mismo el $91 \%$ de los empresarios realiza conciliación permanente de caja bancos.

\section{Capital de trabajo}

En cuanto a la variable de capital de trabajo, el sector obtuvo un 2.7 en promedio el cual es una de las calificaciones más bajas, lo que revela un aspecto importante que cambia de las variables anteriores y es el hecho de que las empresas con mayores ingresos en toda la muestra son las que poseen la menor calificación de la variable, como lo revela el gráfico 12. 
Figura 12. Variable capital de trabajo según el nivel de ingresos

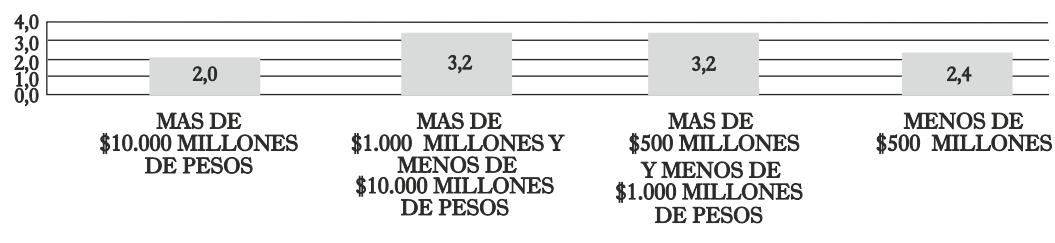

Fuente: Elaboración propia

Es así como se analizarán los aspectos más importantes de esta variable que representan el decremento de la calificación.

Uno de los aspectos que mayor influencia causó en la calificación de la variable, es el hecho de que sólo el $60 \%$ de las empresas concede crédito a sus clientes, por lo cual el $40 \%$ restante afecto la respuesta de las siguientes 5 preguntas al estar en la obligación de dar una respuesta negativa a todas ellas puesto que conservaban una relación y concordancia con la concesión de créditos.

$\checkmark$ Del $60 \%$ de las empresas que conceden créditos a sus clientes el $56 \%$ posee criterios claros y establecidos para dicha concesión.

$\checkmark$ Uno de los aspectos más preocupantes y que afecto en mayor proporción la variable el hecho de que sólo el $51 \%$ de las empresas analiza la capacidad de pago de los clientes antes de conceder el crédito

$\checkmark$ Dentro de las variables que mayor calificación obtuvieron en este aspecto fueron los métodos acertados de toma de decisiones para trabajar con un proveedor particular y la posesión de registros históricos que sustenten las relaciones con los mismos. Dichas variables lograron un $100 \%$ de calificación positiva.

\section{Tributaria}

La variable tributaria obtuvo una de las mejores calificaciones junto con contabilidad, alcanzando una 3.4, lo que revela una relación entre ambas variables y el hecho de que las calificación de la misma se encuentran en 
un nivel muy parejo en todos los niveles de ingresos exceptuando los de menos de 500 millones, que mostraron una calificación menor.

Figura 13. Variable tributaria según el nivel de ingresos

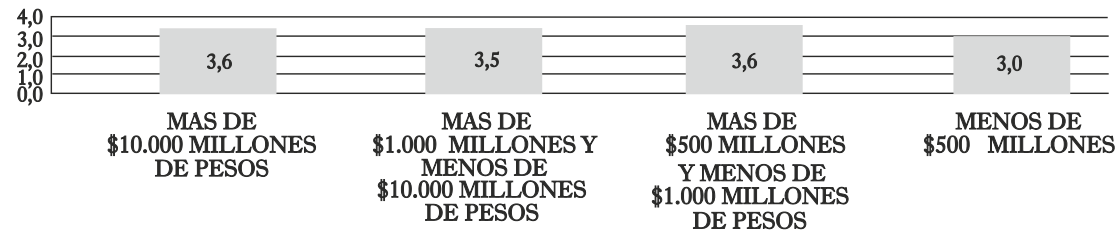

Fuente: Elaboración propia

A continuación se analiza el comportamiento de la variable tributaria mirando los principales factores que influyeron en su calificación.

$\checkmark$ El 96\% de los empresarios afirma conocer claramente las obligaciones tributarias de la empresa y las que se encontraban presentes en el momento de la encuesta.

$\checkmark$ Uno de los factores que mayor afecto el crecimiento de la calificación de la variable el hecho de que solo el $61 \%$ de los encuestados conocía el significado de la información exógena

$\checkmark$ La variable que mayor calificación se obtuvo en esta variable fue la del conocimiento del régimen tributario al que pertenecían las empresas, el cual logró una calificación del 99\%.

$\checkmark$ Finalmente, el factor con menor calificación en esta variable fue que solo al $18 \%$ de los empresarios los ha llamado la DIAN para realizar alguna solicitud, lo cual en algunos aspectos es bueno y malo, debido a que el llamado de la DIAN, no en todos los casos es negativo y puesto a que $83 \%$ de los empresarios no han sido llamados para una solicitud la calificación de la variable es baja. 


\section{Costos}

La variable de costos fue una de las más extensas a evaluar debido a la complejidad de la misma. El resultado obtenido de la variable fue 3.3 una de las segundas mejores calificación del sector.

El siguiente gráfico revela que la mayor calificación la obtuvieron las empresas con más de 10.000 millones de pesos, alcanzando un 3.6 y que las empresas con menos de 500 millones de pesos solo alcanzaron un 2.8.

Figura 14. Variable costos según el nivel de ingresos

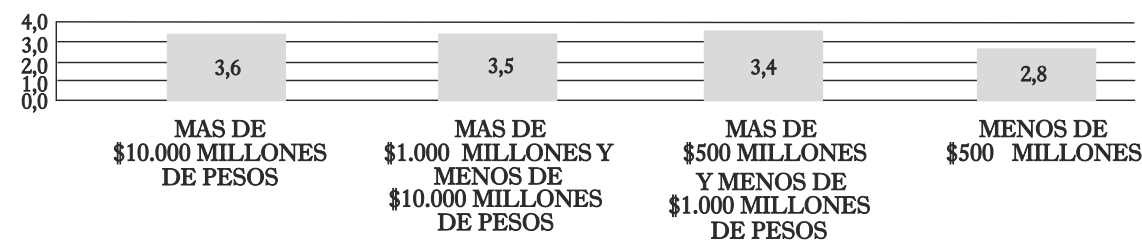

Fuente: Elaboración propia

A continuación se analizarán las respuestas obtenidas en la variable de costos a fin de encontrar los principales aspectos que le permitieron una calificación elevada y las variables que le impidieron incrementar aún más su calificación.

$\checkmark$ Dentro del aspecto de si las empresas llevaban una clara clasificación de costos y gastos el $90 \%$ de los encuestados afirmaron realizarla. Así mismo el $91 \%$ de los mimos afirmó considerar el tema de los costos como una meta clave en los objetivos estratégicos.

$\checkmark$ El 95\% de los empresarios afirmaron manejar un sistema de costos de ventas en sus empresas.

$\checkmark$ El 95\% de los encuestados utiliza la información de sus costos para la fijación de sus precios.

$\checkmark$ Otro de los aspectos que contribuyó con la elevada calificación de la variable es el hecho de que el $100 \%$ de los empresarios tiene un proceso definido para la fijación de precios y tienen claras las consideraciones a la hora de fijarlo, como lo son los cotos, el mercado, la competencia, entre otras. 
$\checkmark$ El 95\% de los encuestados utiliza los costos para mejorar las áreas específicas de la empresa.

$\checkmark$ Uno de los aspectos que contribuyó con la diminución de la calificación del objetivo, es que solo el $76 \%$ de los empresarios conoce las metodologías de costos más eficientes empleadas en el sector

$\checkmark$ Otro de los ámbitos con menor calificación fue el cálculo de márgenes de utilidad y el análisis permanente de su evolución, que solo logró alcanzar un $76 \%$ de realización. El comportamiento de los márgenes calculados es el siguiente:

Figura 15. Márgenes de utilidad que calculan las empresas del sector industrial

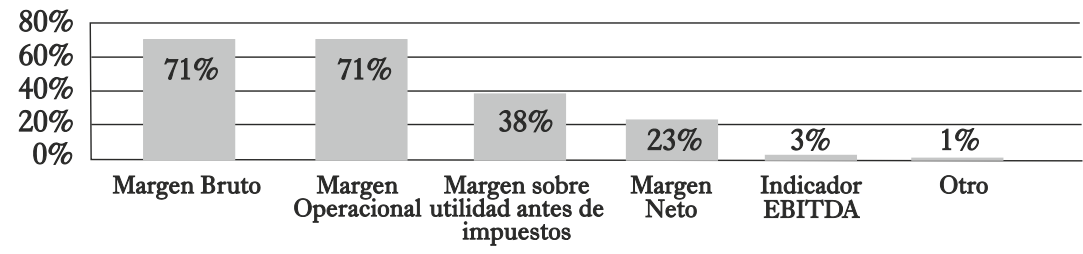

Fuente: Elaboración propia

$\checkmark$ El margen bruto y el margen operacional son los más implementados por las empresas con un $71 \%$, seguido del margen sobre utilidad antes de impuestos con un 38\%. Igualmente el indicador que menos utilizan las empresas es el indicador EBITDA, debido a que la mayoría de empresarios no conoce su funcionalidad.

$\checkmark$ Igualmente solo el $76 \%$ de los empresarios poseen la información contable y de costos disponible para calcular el punto de equilibrio en diferentes periodos para cada uno de sus productos.

$\checkmark$ Otra de las calificaciones más elevadas es el manejo de órdenes de producción o pedido por parte del $98 \%$ de las empresas encuestadas.

$\checkmark$ Finalmente se obtuvo un $100 \%$ en la calificación de la gestión contable y de costos en la empresa, debido a que la totalidad de encuestados ubicó su gestión en un rango lógico de pertenencia (regular, buena 
o excelente). A continuación se muestra la calificación de la gestión contable según el nivel de ingresos

Figura 16. Calificación de los empresarios de su gestión contable en el nivel de ingresos

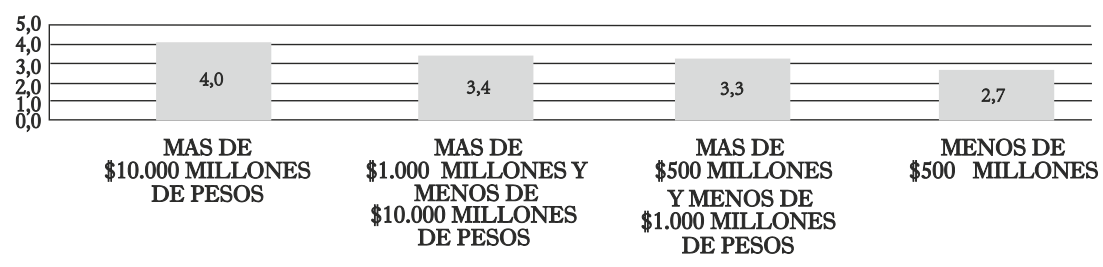

Fuente: Elaboración propia

Se observa que solo las empresas con los mayores ingresos, se asignaron una calificación elevada a la gestión contable y costos.

\section{Análisis de la gestión financiera}

La gestión financiera es la variable más relevante dentro del análisis de las encuestas, debido a su orientación precisa sobre el diagnóstico general del sector industrial. Lo sorprendente e impactante de este aspecto, es el hecho que los empresarios en la calificación solo alcanzaron un 3.1, siendo ésta una de las calificaciones más bajas de todas las variables. A continuación se va a dar explicación a la obtención de dicho resultado.

Dentro del análisis de la variable, se puede observar como lo muestra el Grafico 17 que las empresas con menos de quinientos millones de ingresos son las que obtuvieron la calificación más baja, pero aun así las empresas con ingresos mucho más elevados y que se presumiría son las más fuertes en la gestión financiera mantienen todas tres categorías la misma calificación, mostrando así la grandísima falencia que existe en este aspecto. 
Figura 17. Variable de gestión financiera según el nivel de ingresos

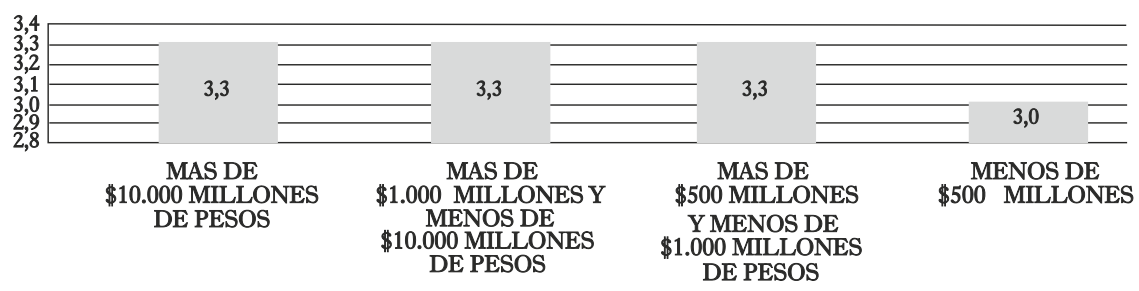

Fuente: Elaboración propia

Por otro lado, dentro de las variables que influyeron dentro de los anteriores resultados tenemos que:

$\checkmark$ Sólo el 64\% de los empresarios afirmaron que realizan un análisis de la información financiera disponible, lo cual es un porcentaje muy bajo que contribuyó con la baja calificación de la variable, debido a que a pesar de que la mayoría de los empresarios poseen bastante información contable, presupuestal y tributaria de la empresa, muy pocos, le realizan un análisis como tal a dicha información.

Dentro de los indicadores financieros que formulan las empresas, se encontró que un $91 \%$ de las empresas realiza los siguientes indicadores:

Figura 18. Indicadores de gestión financiera que se han formulado enlas empresas del sector industrial

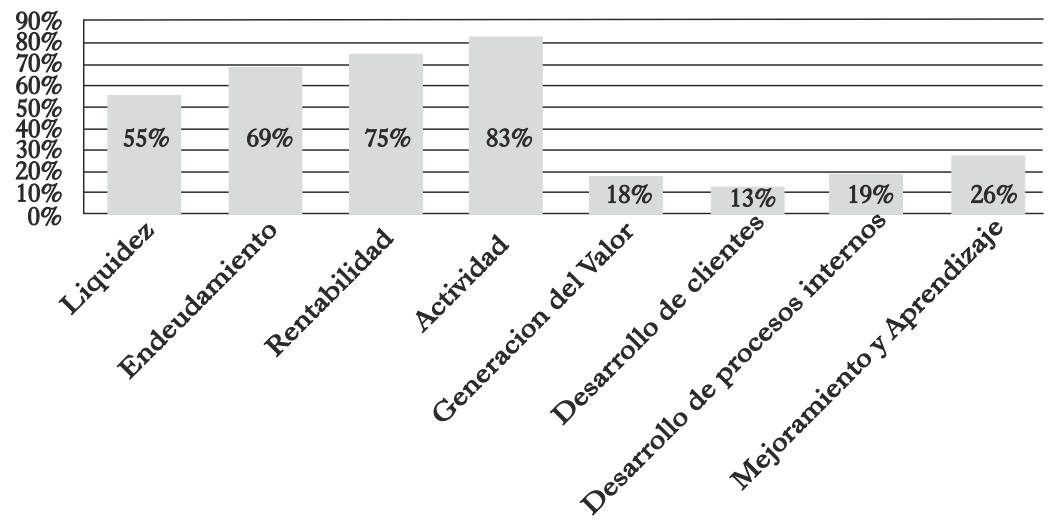

Fuente: Elaboración propia 
$\checkmark$ Se puede encontrar que el indicador más elaborado por las empresas es el de actividad con un $83 \%$, debido a la sugestión de las empresas de mantener sus producciones constantes. Otros de los indicadores más realizados son el de rentabilidad, endeudamiento y liquidez, lo cual es acorde con importancia que le dan los empresarios a las variables de tributaria y costos analizadas anteriormente. El indicador con menor realización dentro del sector es el de desarrollo de clientes, debido al desconocimiento de los empresarios de la importancia y utilidad del mismo.

$\checkmark$ Otro de los factores que tuvo mayor influencia con que la calificación de la variable no fuera más elevada, es el hecho que solo el $55 \%$ de los empresarios genera un informe de los estados financieros hacia sus socios y la empresa, por lo cual solo esa mitad de las empresas encuestadas dedican un tiempo a analizar los resultados encontrados en los estados financieros. Un gran porcentaje de los empresarios no analiza ni genera informes, siendo esto una gran debilidad a la hora de encontrar posibles falencias y soluciones de forma anticipada.

$\checkmark$ Así mismo es curioso observar que el $100 \%$ de las empresas encuestadas contestó, que consideran que sus empresas sí se encuentran generando valor, lo que es contradictorio, porque si no se analiza la gestión realizada durante todos los años no se puede medir de ninguna forma una generación de valor real.

\section{Entorno financiero}

En cuanto al entorno financiero, se puede observar que su calificación general fue de 2.9, por lo cual en la siguiente figura se podrá analizar dicho comportamiento. 
Figura 19. Variable del entorno financiero según el nivel de ingresos

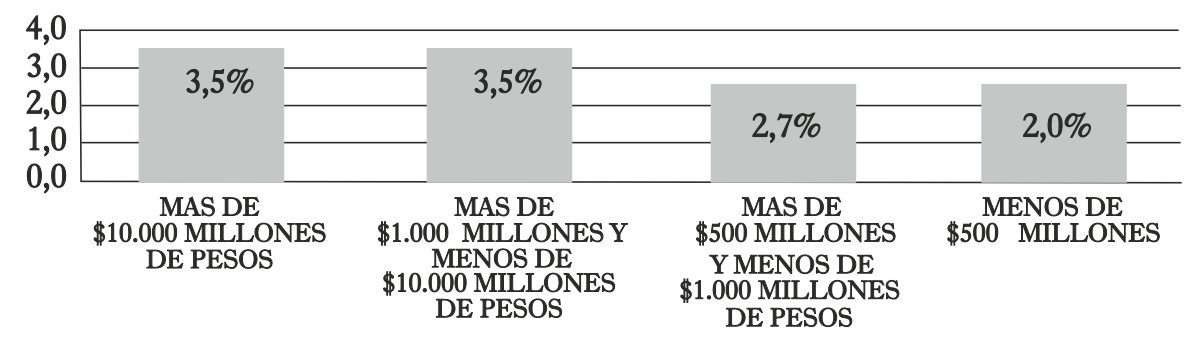

Fuente: Elaboración propia

Como se puede observar, el conocimiento y concientización de la existencia de un entorno financiero que puede favorecer o perjudicar a los empresarios, se encuentra bastante presente en las empresa con mayores ingresos en el sector, mientras que las empresas con menores ingresos no son conscientes de la existencia o de las consecuencias que puede generar dicho entorno.

$\checkmark$ Dentro de los factores que contribuyeron con una calificación favorable de la variable se encuentra el hecho de que más del $90 \%$ de los encuestados afirmó poseer un historial satisfactorio en el sistema financiero, cumplir actualmente con los requisitos de un crédito y conocer productos del sistema financiero que serían de utilidad para la empresa.

$\checkmark$ Así mismo un 86\% afirmó conocer todos los servicios que ofrece un banco, pero contradictoriamente solo el $35 \%$ conocen que es un factoring, el $56 \%$ un leasing, el $40 \%$ un banco de segundo piso y únicamente el $68 \%$ conoce las líneas de crédito para MIPYMES y sus respectivas condiciones. Lo anterior permite observar que a pesar de que los encuestados afirmar tener un conocimiento basto sobre el tema, la realidad muestra una falta de profundización en los mismo y un alarmante descuido, puesto que los empresarios están perdiendo los benéficos que posee el sistema financiero por el desconocimiento del mismo.

$\checkmark$ Por otro lado, dentro de los temas que menor calificación obtuvieron se encuentra el desconocimiento de las Normas Internacionales de Información Financiera, puesto que solo el 26\% de los encuestados poseían 
conocimiento al respecto. Igualmente solo el $24 \%$ conocían el tiempo en el que entraban en vigencia y únicamente el $20 \%$ se está capacitando para trabajar con las NIIF.

\section{DETERMINACIÓN DE FORTALEZAS Y DEBILIDADES DE LA GESTIÓN FINANCIERA}

A fin de darle un curso cuantitativo y cualitativo a la información encontrada en el sector industrial y a las gráficas realizada anteriormente, se decide establecer un parámetro de control de los resultados obtenidos. Las variables analizadas serán sometidas a una estratificación cuantitativa y cualitativa, la cual medirá las fortalezas y debilidades del sector.

La clasificación es la siguiente:

Tabla 2. Escala de clasificación de fortalezas y debilidades

\begin{tabular}{|c|c|}
\hline CALIFICACIONES & CRITERIO \\
\hline Resultado entre 3.5 y 4.0 & FORTALEZA MAYOR \\
\hline Resultado entre 3.0 y 3.49 & FORTALEZA MENOR \\
\hline Resultado entre 2.51 y 2.99 & DEBILIDAD MENOR \\
\hline Resultado igual o inferior a 2.50 & DEBILIDAD MAYOR \\
\hline
\end{tabular}

Fuente: Elaboración propia

Según los anteriores criterios, las calificaciones obtenidas en el sector industrial son:

Tabla 3. Calificación de fortalezas y debilidades de la gestión financiera del sector industrial

\begin{tabular}{|c|c|l|}
\hline VARIABLE & CRITERIO & \multicolumn{1}{c|}{ DESCRIPCION } \\
\hline CONTABILIDAD & $\begin{array}{l}\text { Se caracteriza como una fortaleza menor, a pesar de } \\
\text { que es muy próxima a convertirse en una fortaleza } \\
\text { mayor. Dentro de los aspectos más relevantes para que } \\
\text { esta variable obtuviera su calificación, se encuentra el } \\
\text { hecho de que casi el 100\% de los encuestados lleva } \\
\text { su contabilidad, registran y actualizan diariamente sus } \\
\text { operaciones, conservan sus soportes operacionales } \\
\text { y evalúan sus estados financieros para detectar } \\
\text { incoherencias. }\end{array}$ \\
\hline
\end{tabular}




\begin{tabular}{|c|c|c|}
\hline $\begin{array}{l}\text { PRESUPUESTO } \\
3.3\end{array}$ & $\begin{array}{c}\text { FORTALEZA } \\
\text { MENOR }\end{array}$ & $\begin{array}{l}\text { Dentro de los aspectos que permitieron una calificación } \\
\text { elevada para esta variable, se encuentra el hecho de que } \\
\text { más del } 70 \% \text { de los encuestados afirmó realizar un proceso } \\
\text { de presupuestario soportado en la investigación objetiva } \\
\text { del mercado, una estructura clara de los presupuestos y el } \\
\text { respectivo análisis del capital de trabajo de la empresa. }\end{array}$ \\
\hline $\begin{array}{l}\text { CAPITAL DE TRABAJO } \\
\qquad 2.7\end{array}$ & $\begin{array}{l}\text { DEBILIDAD } \\
\text { MENOR }\end{array}$ & $\begin{array}{l}\text { Dentro de los aspectos que impulsaron a que la variable se } \\
\text { refleje como una debilidad menor, se encuentra el hecho de } \\
\text { que menos del } 60 \% \text { de las empresas que conceden crédito a } \\
\text { sus clientes poseen criterios claros y establecidos para ello, } \\
\text { ni analizan la capacidad de pago de los clientes. }\end{array}$ \\
\hline $\begin{array}{l}\text { TRIBUTARIA } \\
3.4\end{array}$ & $\begin{array}{c}\text { FORTALEZA } \\
\text { MENOR }\end{array}$ & $\begin{array}{l}\text { A pesar de clasificar como una fortaleza menor, es posible } \\
\text { que con las correcciones y estrategias adecuadas, la variable } \\
\text { pase a ser una fortaleza mayor. Dentro de los aspectos que } \\
\text { lograron una elevada calificación se encuentra el hecho de } \\
\text { que, más del } 90 \% \text { de los encuestados conoce claramente sus } \\
\text { obligaciones tributarias y el régimen al que pertenecen. }\end{array}$ \\
\hline $\begin{array}{l}\text { COSTOS } \\
3.3\end{array}$ & $\begin{array}{l}\text { FORTALEZA } \\
\text { MENOR }\end{array}$ & $\begin{array}{l}\text { Dentro de los aspectos que clasifican a la variable como } \\
\text { una fortaleza menor se encuentra el hecho de que más del } \\
90 \% \text { de los encuestados posee una clasificación de costos y } \\
\text { gastos, manejan un sistema de costos de ventas, utilizan los } \\
\text { costos como base para fijar los precios, tienen un proceso } \\
\text { definido de fijación de precios y utilizan la información de } \\
\text { los costos para mejorar en áreas específicas de la empresa. }\end{array}$ \\
\hline $\begin{array}{l}\text { ANÁLISIS GESTIÓN } \\
\text { FINANCIERA } \\
3.1\end{array}$ & $\begin{array}{l}\text { FORTALEZA } \\
\text { MENOR }\end{array}$ & $\begin{array}{l}\text { Lo que clasificó al análisis de la gestión financiera como una } \\
\text { fortaleza menor, fue que más del } 90 \% \text { de los empresarios } \\
\text { realiza indicadores financieros y consideran que sus empre- } \\
\text { sas sí están generando valor. }\end{array}$ \\
\hline $\begin{array}{l}\text { ENTORNO FINANCIERO } \\
\qquad 2.9\end{array}$ & $\begin{array}{l}\text { DEBILIDAD } \\
\text { MENOR }\end{array}$ & $\begin{array}{l}\text { Dentro de los aspectos que ubican a la variable como una } \\
\text { debilidad menor se encuentra el hecho que, menos del } \\
30 \% \text { conoce las Normas Internacionales de Información } \\
\text { Financiera, su vigencia y se encuentran en proceso de } \\
\text { capacitación de las mismas. }\end{array}$ \\
\hline
\end{tabular}

Fuente: Elaboración propia

Según la Tabla 3, se puede observar que el sector industrial clasifica 5 de las 7 variables analizadas como fortalezas menores, las cuales son: contabilidad, presupuestos, tributaria, costos y análisis de la gestión financiera. Por otro lado, dentro de las debilidades menores, se encuentra el capital financiero y el entorno financiero.

\section{FORTALEZAS Y DEBILIDADES DE CADA UNA DE LAS VARIABLES ANALIZADAS Y LAS ESTRATEGIAS A REALIZAR}

A continuación se expondrá detalladamente las principales fortalezas y debilidades de cada una de las variables analizadas y las posibles estrategias a implementar en las empresas del sector industrial, a fin de 
que los resultados de las variables se conviertan en fortalezas mayores, las cuales le puedan generar una ventaja competitiva a las empresas. Todo lo anterior se expondrá mediante un cuadro que permite analizar las fortalezas y debilidades de cada variable y postular las mejores estrategias.

La valoración para determinar las fortalezas de las variables, fue la obtención de resultados con un porcentaje igual o mayor al $80 \%$ y las debilidades con un porcentaje igual o menor al $79 \%$.

Tabla 4. Fortalezas, debilidades y estrategias de la variable contabilidad

\begin{tabular}{|c|c|c|c|}
\hline VARIABLE & FORTALEZAS & DEBILIDADES & ESTRATEGIAS \\
\hline \multirow{7}{*}{ CONTABILIDAD } & $\begin{array}{l}\text { El } 98 \% \text { de la totalidad de los } \\
\text { encuestados registran de } \\
\text { manera permanente todas las } \\
\text { operaciones que realiza la } \\
\text { empresa }\end{array}$ & $\begin{array}{l}\text { Solo el } 64 \% \text { de } \\
\text { los encuestados } \\
\text { afirmó poseer un } \\
\text { profesional en el } \\
\text { tema contable } \\
\text { que realice la } \\
\text { contabilidad }\end{array}$ & \multirow{2}{*}{$\begin{array}{l}\text { Para las empresas con } \\
\text { menores ingresos, se } \\
\text { puede contratar a un } \\
\text { profesional contable } \\
\text { como staff, a fin de que } \\
\text { guie el correcto } \\
\text { desempeño contable de } \\
\text { la empresa y lo } \\
\text { estandarice bajo las } \\
\text { normas contables } \\
\text { Colombianas }\end{array}$} \\
\hline & $\begin{array}{l}\text { El } 100 \% \text { de las empresas } \\
\text { afirmó conservar de manera } \\
\text { adecuada todos los soportes de } \\
\text { las operaciones realizadas } \\
\text { como facturas, recibos etc. }\end{array}$ & $\begin{array}{l}\text { Solo el } 64 \% \text { de } \\
\text { los encuetados } \\
\text { poseer criterios } \\
\text { claros para } \\
\text { seleccionar el } \\
\text { contador de la } \\
\text { empresa }\end{array}$ & \\
\hline & $\begin{array}{l}\text { El } 96 \% \text { de las empresas } \\
\text { analizadas en el sector } \\
\text { industrial afirman llevar } \\
\text { contabilidad en la empresa. }\end{array}$ & \multirow{5}{*}{$\begin{array}{l}\text { El } 8 \% \text { de los } \\
\text { encuestados } \\
\text { afirman no llevar } \\
\text { su contabilidad } \\
\text { de acuerdo con } \\
\text { las normas } \\
\text { contables } \\
\text { Colombianas }\end{array}$} & \multirow{3}{*}{$\begin{array}{l}\text { Establecer criterios claros } \\
\text { para la selección de los } \\
\text { profesionales contables, } \\
\text { basándose en un correcto } \\
\text { registro y control de las } \\
\text { mejoras en la gestión } \\
\text { contable que realicen los } \\
\text { profesionales contables, a } \\
\text { fin de medir los mejores } \\
\text { desempeños. }\end{array}$} \\
\hline & $\begin{array}{l}\text { El } 86 \% \text { de las empresas poseen } \\
\text { actualizados y con máximo un } \\
\text { mes de retraso los estados } \\
\text { financieros }\end{array}$ & & \\
\hline & $\begin{array}{l}\text { El } 100 \% \text { de los empresarios } \\
\text { encuestados afirmó que } \\
\text { procuraba poseer información } \\
\text { actualizada cada día }\end{array}$ & & \\
\hline & $\begin{array}{l}\text { El } 89 \% \text { de los gerentes evalúa y } \\
\text { examina de forma permanente } \\
\text { los estados financieros a fin de } \\
\text { detectar incorrecciones }\end{array}$ & & $\begin{array}{l}\text { Capacitaciones y } \\
\text { actualizaciones } \\
\text { constantes }\end{array}$ \\
\hline & $\begin{array}{l}\text { El 95\% de los } \\
\text { toma sus empresarios } \\
\text { basándose en los estados } \\
\text { financieros }\end{array}$ & & $\begin{array}{l}\text { Implementación de un } \\
\text { software contable }\end{array}$ \\
\hline
\end{tabular}

Fuente: Elaboración propia 
Tabla 5. Fortalezas, debilidades y estrategias de la variable presupuesto

\begin{tabular}{|c|c|c|c|}
\hline VARIABLE & FORTALEZAS & DEBILIDADES & ESTRATEGIAS \\
\hline \multirow{4}{*}{ PRESUPUESTOS } & $\begin{array}{l}\text { En cuanto al aspecto de } \\
\text { la realización, estructura } \\
\text { y claridad de los presu- } \\
\text { puestos se obtuvo un } \\
84 \% \text { de las empresas que } \\
\text { lo implementaba }\end{array}$ & $\begin{array}{l}\text { El } 75 \% \text { de las empresas } \\
\text { poseen un proceso de } \\
\text { presupuestación }\end{array}$ & \multirow{4}{*}{$\begin{array}{l}\text { Realizar protocolos de } \\
\text { presupuestación, que } \\
\text { permitan la estandari- } \\
\text { zación del proceso pre- } \\
\text { supuestal y del análisis } \\
\text { del mismo } \\
\text { Implementar diversas } \\
\text { herramientas de análi- } \\
\text { sis del presupuesto de } \\
\text { ventas como lo son los } \\
\text { pronósticos, análisis } \\
\text { estadísticos y series his- } \\
\text { tóricas, a fin de obtener } \\
\text { una mayor precisión y } \\
\text { control de los presu- } \\
\text { puestos }\end{array}$} \\
\hline & $\begin{array}{l}\text { El } 84 \% \text { de las empresas } \\
\text { compara los presupues- } \\
\text { tos con la realidad de } \\
\text { manera permanente y di- } \\
\text { chas comparaciones son } \\
\text { fuente de corrección. }\end{array}$ & $\begin{array}{l}\text { El } 75 \% \text { de los empresa- } \\
\text { rios afirmó soportar sus } \\
\text { presupuestos de ventas } \\
\text { en investigación objetiva } \\
\text { del mercado }\end{array}$ & \\
\hline & $\begin{array}{l}\text { El } 96 \% \text { de las empresas } \\
\text { determinan las necesida- } \\
\text { des de capital de trabajo }\end{array}$ & \multirow{2}{*}{$\begin{array}{l}\text { El } 78 \% \text { de los encues- } \\
\text { tados afirmó utilizar de } \\
\text { herramientas de análisis } \\
\text { para el presupuesto de } \\
\text { ventas }\end{array}$} & \\
\hline & $\begin{array}{l}\text { El } 91 \% \text { de los empresa- } \\
\text { rios realiza conciliación } \\
\text { permanente de caja ban- } \\
\text { cos. }\end{array}$ & & \\
\hline
\end{tabular}

Fuente: Elaboración propia

Tabla 6. Fortalezas, debilidades y estrategias de la variable capital de trabajo

\begin{tabular}{|c|c|c|c|}
\hline VARIABLE & FORTALEZAS & DEBILIDADES & ESTRATEGIAS \\
\hline \multirow{3}{*}{ CAPITAL DE TRABAJO } & \multirow{3}{*}{$\begin{array}{l}\text { El } 100 \% \text { de los encuestados } \\
\text { posee métodos acertados } \\
\text { de toma de decisiones para } \\
\text { trabajar con un proveedor } \\
\text { particular y posee los regis- } \\
\text { tros históricos que susten- } \\
\text { ten las relaciones con los } \\
\text { mismos }\end{array}$} & $\begin{array}{l}\text { Solo el } 60 \% \text { de las em- } \\
\text { presas concede crédito a } \\
\text { sus clientes }\end{array}$ & \multirow{3}{*}{$\begin{array}{l}\text { Realizar manuales } \\
\text { de procesos para } \\
\text { la concesión de los } \\
\text { créditos, en los cuales } \\
\text { se establezcan los } \\
\text { procesos y métodos } \\
\text { necesarios para } \\
\text { conceder los créditos } \\
\text { (solicitudes, análisis } \\
\text { de las empresas, } \\
\text { capacidad de pago, } \\
\text { etc.) y los riesgos } \\
\text { que genera para } \\
\text { la empresa dichos } \\
\text { créditos. }\end{array}$} \\
\hline & & $\begin{array}{l}\text { Solo el } 56 \% \text { posee crite- } \\
\text { rios claros y establecidos } \\
\text { para conceder créditos }\end{array}$ & \\
\hline & & $\begin{array}{l}\text { Solo el } 51 \% \text { de las empre- } \\
\text { sas analiza la capacidad } \\
\text { de pago de los clientes } \\
\text { antes de conceder el cré- } \\
\text { dito }\end{array}$ & \\
\hline
\end{tabular}

Fuente: Elaboración propia 
Tabla 7. Fortalezas, debilidades y estrategias de la variable tributaria

\begin{tabular}{|c|c|c|c|}
\hline VARIABLE & FORTALEZAS & DEBILIDADES & ESTRATEGIAS \\
\hline \multirow{3}{*}{ TRIBUTARIA } & $\begin{array}{l}\text { El } 96 \% \text { de los empresa- } \\
\text { rios encuetados afirma } \\
\text { conocer claramente las } \\
\text { obligaciones tributarias } \\
\text { de la empresa }\end{array}$ & \multirow{3}{*}{$\begin{array}{l}\text { Solo el } 61 \% \text { de los en- } \\
\text { cuestados conocía el } \\
\text { significado de la informa- } \\
\text { ción exógena }\end{array}$} & \multirow{3}{*}{$\begin{array}{l}\text { Unir las estrategias de contabi- } \\
\text { lidad con las de tributaria y so- } \\
\text { licitarle al profesional contable } \\
\text { que capacite al gerente en el } \\
\text { conocimiento contable y tribu- } \\
\text { tario básico para las empresas } \\
\text { Realizar planeación tributaria } \\
\text { entre la gerencia y el profesio- } \\
\text { nal contable }\end{array}$} \\
\hline & $\begin{array}{l}\text { El } 99 \% \text { de los encuesta- } \\
\text { dos tenía claro el régimen } \\
\text { tributario al que pertene- } \\
\text { ce su empresa }\end{array}$ & & \\
\hline & $\begin{array}{l}\text { El } 83 \% \text { de los empresa- } \\
\text { rios no han sido llamados } \\
\text { para una solicitud en la } \\
\text { DIAN }\end{array}$ & & \\
\hline
\end{tabular}

Fuente: Elaboración propia

Tabla 8. Fortalezas, debilidades y estrategias de la variable costos

\begin{tabular}{|c|c|c|c|}
\hline VARIABLE & FORTALEZAS & DEBILIDADES & ESTRATEGIAS \\
\hline \multirow{6}{*}{ COSTOS } & $\begin{array}{l}\text { El } 90 \% \text { las empresas llevaban } \\
\text { una clara clasificación de cos- } \\
\text { tos y gastos }\end{array}$ & $\begin{array}{l}\text { El } 76 \% \text { de los empresa- } \\
\text { rios conoce las meto- } \\
\text { dologías de costos más } \\
\text { eficientes empleadas en } \\
\text { el sector }\end{array}$ & \multirow{3}{*}{$\begin{array}{l}\text { Realizar benchmarking del } \\
\text { desempeño de la gestión de } \\
\text { costos de la empresa con los } \\
\text { líderes del mercado, a fin de } \\
\text { lograr focalizar las estrate- } \\
\text { gias de gestión y las mejores } \\
\text { metodologías de costos a } \\
\text { implementar }\end{array}$} \\
\hline & $\begin{array}{l}\text { El } 91 \% \text { de los encuestados } \\
\text { afirmó considerar el tema } \\
\text { de los costos como una meta } \\
\text { clave en los objetivos estraté- } \\
\text { gicos }\end{array}$ & $\begin{array}{l}\text { Solo el } 76 \% \text { de los en- } \\
\text { cuestados calcula el mar- } \\
\text { gen de utilidad y realiza } \\
\text { el análisis permanente } \\
\text { de su evolución }\end{array}$ & \\
\hline & $\begin{array}{l}\text { El } 95 \% \text { de los empresarios } \\
\text { afirmaron manejar un siste- } \\
\text { ma de costos de ventas en } \\
\text { sus empresas }\end{array}$ & $\begin{array}{l}\text { Solo el } 3 \% \text { de los encues- } \\
\text { tados realizan el indica- } \\
\text { dor EBITDA }\end{array}$ & \\
\hline & $\begin{array}{l}\text { El } 95 \% \text { de los encuestados } \\
\text { utiliza la información de sus } \\
\text { costos para la fijación de sus } \\
\text { precios }\end{array}$ & \multirow{3}{*}{$\begin{array}{l}\text { Solo el } 76 \% \text { de los em- } \\
\text { presarios poseen la in- } \\
\text { formación contable y de } \\
\text { costos disponible para } \\
\text { calcular el punto de } \\
\text { equilibrio en diferentes } \\
\text { periodos para cada uno } \\
\text { de sus productos }\end{array}$} & \multirow{3}{*}{$\begin{array}{l}\text { Calcular los indicadores que } \\
\text { permitan ubicar a la empre- } \\
\text { sa en la escala de desempe- } \\
\text { ño industrial y lograr propo- } \\
\text { ner estrategias para mejorar } \\
\text { la generación de valor em- } \\
\text { presarial }\end{array}$} \\
\hline & $\begin{array}{l}\text { El } 100 \% \text { de los empresarios } \\
\text { tiene un proceso definido } \\
\text { para la fijación de precios }\end{array}$ & & \\
\hline & $\begin{array}{l}\text { Se obtuvo un } 100 \% \text { en la cali- } \\
\text { ficaron de la gestión contable } \\
\text { y de costos en la empresa, } \\
\text { debido a que la totalidad de } \\
\text { encuestados ubico su gestión } \\
\text { en el rango lógico de perte- } \\
\text { nencia }\end{array}$ & & \\
\hline
\end{tabular}

Fuente: Elaboración propia 
Tabla 9. Fortalezas, debilidades y estrategias de la variable análisis de la gestión financiera

\begin{tabular}{|c|c|c|c|}
\hline VARIABLE & FORTALEZAS & DEBILIDADES & ESTRATEGIAS \\
\hline \multirow{2}{*}{$\begin{array}{c}\text { ANÁLISIS DE LA } \\
\text { GESTIÓN FINANCIERA }\end{array}$} & $\begin{array}{l}\text { El } 91 \% \text { de las empresas } \\
\text { realiza indicadores de } \\
\text { gestión financiera }\end{array}$ & $\begin{array}{l}\text { Sólo el } 64 \% \text { de los } \\
\text { empresarios afir- } \\
\text { maron que rea- } \\
\text { lizan un análisis } \\
\text { de la información } \\
\text { financiera dispo- } \\
\text { nible }\end{array}$ & \multirow{2}{*}{$\begin{array}{l}\text { Realizar una unión de los pro- } \\
\text { tocolos, registros y manuales } \\
\text { planteados en las otras variables } \\
\text { y complementar el hecho de } \\
\text { que la parte operativa financiera } \\
\text { sí se está realizando y hacer un } \\
\text { análisis mensual o trimestral de } \\
\text { las gestión financiera que se está } \\
\text { desarrollando, a fin de descubrir } \\
\text { posibles inconvenientes y plas- } \\
\text { mar estrategias de prevención y } \\
\text { control que logren anticiparse a } \\
\text { los resultados. }\end{array}$} \\
\hline & $\begin{array}{l}\text { El } 100 \% \text { de las empresas } \\
\text { encuestadas contesto } \\
\text { que consideras que sus } \\
\text { empresas sí están y han } \\
\text { generado valor }\end{array}$ & $\begin{array}{l}\text { Solo el } 55 \% \text { de los } \\
\text { empresarios gene- } \\
\text { ra un informe de } \\
\text { los estados finan- } \\
\text { cieros hacia sus so- } \\
\text { cios y la empresa }\end{array}$ & \\
\hline
\end{tabular}

Fuente: Elaboración propia

Tabla 10. Fortalezas, debilidades y estrategias de la variable entrono financiero

\begin{tabular}{|c|c|c|c|}
\hline VARIABLE & FORTALEZAS & DEBILIDADES & ESTRATEGIAS \\
\hline \multirow{7}{*}{$\begin{array}{l}\text { ENTRONO } \\
\text { FINANCIERO }\end{array}$} & $\begin{array}{l}\text { Más del } 90 \% \text { de los encuesta- } \\
\text { dos afirmó poseer un historial } \\
\text { satisfactorio en el sistema fi- } \\
\text { nanciero }\end{array}$ & $\begin{array}{l}\text { Solo el } 35 \% \text { de los encues- } \\
\text { tados conocen que es un } \\
\text { factoring }\end{array}$ & \multirow{7}{*}{$\begin{array}{l}\text { Asistir a las capaci- } \\
\text { taciones, charlas y } \\
\text { coloquios que ofre- } \\
\text { cen las cámaras de } \\
\text { comercio y las insti- } \\
\text { tuciones educativas } \\
\text { sobre el entorno } \\
\text { financiero de las } \\
\text { empresas }\end{array}$} \\
\hline & $\begin{array}{l}\text { El } 86 \% \text { de los encuestados afir- } \\
\text { mó conocer todos los servicios } \\
\text { que ofrece un banco }\end{array}$ & $\begin{array}{l}\text { El } 56 \% \text { de los encuestados } \\
\text { afirmó tener conocimiento } \\
\text { de los leasing }\end{array}$ & \\
\hline & $\begin{array}{l}\text { Más del } 90 \% \text { de los encues- } \\
\text { tados afirma cumplir actual- } \\
\text { mente con los requisitos de un } \\
\text { crédito }\end{array}$ & $\begin{array}{l}\text { Solo el } 40 \% \text { de los encuesta- } \\
\text { dos conoce qué es un banco } \\
\text { de segundo piso }\end{array}$ & \\
\hline & \multirow{4}{*}{$\begin{array}{l}\text { Más del } 90 \% \text { de los encues- } \\
\text { tados afirma conocer los pro- } \\
\text { ductos del sistema financiero } \\
\text { que serían de utilidad para la } \\
\text { empresa }\end{array}$} & $\begin{array}{l}\text { Únicamente el } 68 \% \text { conoce } \\
\text { las líneas de crédito para } \\
\text { MIPYMES y sus respectivas } \\
\text { condiciones }\end{array}$ & \\
\hline & & $\begin{array}{l}\text { Solo el } 26 \% \text { de los encues- } \\
\text { tados poseían conocimiento } \\
\text { de las NIIF }\end{array}$ & \\
\hline & & $\begin{array}{l}\text { Solo el } 24 \% \text { de los encuesta- } \\
\text { dos conocían el tiempo en } \\
\text { el que entraban en vigencia } \\
\text { las NIIF }\end{array}$ & \\
\hline & & $\begin{array}{l}\text { Únicamente el } 20 \% \text { de } \\
\text { los encuestados se está } \\
\text { capacitando para trabajar } \\
\text { con las NIIF. }\end{array}$ & \\
\hline
\end{tabular}

Fuente: Elaboración propia 


\section{CONCLUSIONES Y RECOMENDACIONES}

- La gestión financiera realizada por las empresas del sector industrial, permite observar que su desempeño es satisfactorio, puesto que revela grandes fortalezas en el aspecto operativo de la gestión; es decir en la realización a cabalidad y con elevados estándares de la contabilidad, el manejo tributario, los presupuestos y los costos, pero con grandes propósitos a realizar un mejor reconocimiento de los factores y entidades externas a la empresa que pueden generarle grandes beneficios.

El cambio más importante para este sector es realizar un análisis exhaustivo a toda la parte operativa financiera que ya se maneja, puesto que de nada le sirve al empresario sacar una lista de indicadores, estados financieros, márgenes, entre otros, si en realidad no se analiza la razón de ser de dichos datos y se toman las medidas correctivas para que la empresa se anticipe a las situaciones adversas o de beneficio y plantee estrategias que logren darle un valor agregado a la misma.

- En concordancia con lo planteado por Espinosa (2013), para que el corredor industrial de Boyacá adquiera una visión competitiva y sostenible, debe consolidar sus proceso de desarrollo, avances tecnológicos e innovación, los cuales según el presente trabajo se pueden empezar a implementar en las empresas bajo los nuevos mecanismos de la gestión financiera, buscando alimentar bases de datos empresariales con manuales y protocolos estandarizados, que le den a la empresa un valor agregado en su gestión y que a su vez, permita tener un consolidado de información para así generar un proceso de análisis de la gestión financiera que logre posicional en el mundo al corredor industrial de Boyacá.

- Como lo plantea Correa y otros (2009), una de las formas de mejorar las condiciones actuales de las empresas es la implementación de un modelo de gestión financiera integral, el cual para los autores se basa en la unión administrativa, técnica, legal, internacional y contable financiero, pero que según el diagnóstico encontrado, para el sector industrial se puede complementar integrando:

- Proceso financiero operativo: Contabilidad, Presupuestos, Tributaria y Costos. 
- Proceso financiero externo: Capital de Trabajo y Entorno Financiero.

- Proceso de análisis financiero: Análisis de la Gestión Financiera.

Mostrando así, que la unión de las variables planteadas por los autores y los procesos planteados por el diagnóstico, permitirán que el sector industrial de Boyacá, logre afianzar las fortalezas que posee y convierta sus debilidades en fortalezas.

- Según la investigación de Burbano y otros (2006), el empirismo empresarial presentado por las empresas del sector industrial de Boyacá, las hace poco atractivas para la inversión de empresas extranjeras y el acceso a créditos bancarios. Pero al analizar la gestión financiera de las empresas, se descubre que el empirismo traspasado de generación en generación ha sido meramente de la actividad productiva de las empresas. Por lo cual se puede concluir que actualmente las empresas del sector industrial siguen manteniendo su conocimiento empírico y de experiencia adquirido de generación en generación, pero han venido presentando una actualización y mejora continua en su manejo financiero, por lo cual se debe explotar el deseo de los empresarios por salir adelante y empaparse del tema financiero, para capacitarlos sobre las mejores alternativas de gestión y manejo financiero.

- Se recomienda que los empresarios del sector industrial se capaciten en cuanto a los términos financieros necesarios para llevar a cabo una buena gestión y en cuanto a los nuevos métodos de gestión financiera.

- Se recomienda la implementación de las estrategias planteadas, a fin de que los empresarios logren convertir sus falencias de gestión financiera en fortalezas empresariales 


\section{REFERENCIAS BIBLIOGRÁFICAS}

Burbano, R., Castillo, D., y Chaves, C. (2006). Modelo de estructura financiera para las pymes del sector metalmecánico del corredor industrial de Boyacá. Recuperado 02/02/2014 de: http://www. revistasjdc.com/main/index.php/ccient/issue/view/1

Calvopiña, L. (2010). Implementación de un sistema contable computarizado en la fábrica alfarera ubicada en el Valle de Tumbaco provincia de Pichincha para el periodo del 01 al 31 de enero del 2008. Universidad Técnica de Cotopaxi.

Correa, J., Ramírez, L., y Castaño, C. (2009). Modelo de gestión financiera integral para MIPYMES en Colombia. Universidad de Antioquia. pp. 187-20.

Departamento Nacional de Planeación. (2007). Agenda interna para la productividad y la competitividad. Documento regional Boyacá.

Espinosa, J. (2013). Análisis prospectivo de la región económica de planificación del corredor de industrial de Boyacá al horizonte del año 2019. Universidad Externado de Colombia.

Ministerio de Hacienda y Credito Público. (2011). Aspectos generales del proceso presupuestal Colombiano.

Mojica, F. (2010). Agenda prospectiva de investigación y desarrollo tecnológico de la cadena láctea en Colombia. Recuperado 05/01/2014 de: http://www.agronet.gov.co/www/docs_agronet/200831311504_L\%E1cteos.pdf

Muñoz, M. (2010). Interpretación de los estados financieros de la caja de ahorros del profesorado de la universidad de los andes (CAPROFULA). Universidad de los Andes Núcleo Universitario Rafael Rangel. Ochoa, GH. (2009). Administracion financiera. México: Editorial McGraw - Hill.

Ortiz,A. (2006). Análisis financiero aplicado y principios de administración financiera. Bogota: Universidad Externado de Colombia.

Sánchez, A., Domínguez, M.,Miranda, L. y Gonzáles, N. (2011). Etapas del diseño de un sistema de contabilidad de costos. pp. 16. Recuperado 06/01/2014 de: http://www.itson.mx/publicaciones/pacioli/ 
Documents/no72/61c_-_etapas_del_diseno_de_un_sistema_de_ contabilidad_de_costos1.pdf

Santoyo, R. (2011). Evaluación del proceso de gestión de calidad en las fabricas procesadoras de queso del Municipio de Belén: Aplicación a la estandarización del proceso de producción Planta Ibel. Universidad Nacional de Colombia. Sarmiento, R. (2004). Contabilidad general actualizada. Ecuador: Voluntad

Torres, C. (2012). ¿Agregan valor las áreas de gestión humana a las organizaciones del sector industrial de Duitama y Sogamoso (Boyacá)?. Universidad Nacional de Colombia.

Vidal, J. (2010). Cumplimiento de las obligaciones tributarias del impuesto sobre la renta por los contribuyentes del c.c Jabreco Center, Municipio Valera, Estado Trujillo. Universidad de los Ándes Núcleo Rafael Rangel. 